\title{
END OF SERVICE SCENARIO FOR UNIVERSITIES' INFORMATIC EQUIPMENT: RECOVERY AND REPAIR AS EDUCATIONAL AND RESEARCH TOOL FOR CIRCULAR ECONOMY AND URBAN MINING
}

\author{
Alessandra Bonoli ${ }^{1}$, Nicoletta Dolci ${ }^{1,2}$, Eleonora Foschi ${ }^{1, \star}$, Francesco Lalli ${ }^{1}$, Daria \\ Prandstraller ${ }^{2}$ and Sara Zanni ${ }^{1}$ \\ ${ }^{1}$ Department of Civil, Chemical, Environmental and Materials Engineering (DICAM), University of Bologna, via Terracini 28, 40131 \\ Bologna, Italy \\ ${ }^{2}$ Technical Unit for Waste Management (NU.TE.R), University of Bologna, via Filippo Re 10, 40126 Bologna, Italy
}

Article Info:
Received:
30 June 2018
Revised:
12 October 2018
Accepted:
7 December 2018
Available online:
21 December 2018
Keywords:
Electrical electronic equipment
Refurbishment
Urban mining
Circular economy
Education
University of Bologna

\section{INTRODUCTION}

Electronics has experienced exponential penetration in daily life. Everything, from product to services, is moving toward digitalisation, and people resorts to electronic devices with increasing frequency to quickly solve routine tasks. The acceleration on electronic devices consumption has been carried on by smart digitalisation that has also hastened the transition toward virtual communication system represented by information and communication technologies (ICT). For example, only in $2016,1.5$ billion units of smartphones were sold on the market compared to 680 million units sold in 2012. According to recent statistic, over 28 percent of the world population owned a smart communication device in 2016 (https://www.statista.com/ statistics/263437/global-smartphone-sales-to-end-userssince-2007/). At the same time, digitalisation is influencing manufacturing and services industry taking advantage of open data system for research as well as treatments. Open and big data management needs high performance computing that has been contributing to implement tech- nologically advanced multi-core processors, which require continuous maintenance and, often, replacement. The United Nations Environment Program (UNEP - 2009) assesses that by 2020 - the quantity of dismissed computers will increase 5 times over current levels. According to Cui and Forssberg (2003), the production of electrical and electronic equipment (EEE) is one of the fastest growing industrial sector. In 2016, this sector represented a world market share of $14.6 \%$, with a remarkable growth accomplished in the short term and with good perspective in the long term (https://www.statista.com/statistics/263437/global-smartphone-sales-to-end-users-since-2007/). However, with the rapid advancement or progress in technology and the consequent fast obsolescence, consumer demand and strong incentives for consumption bring along a drastically reduced lifespan and increase faster replacement rates of most EEEs (Borthakur et al., 2017), with the consequence of increasing quantity of electronic waste, E-waste (Gu et al., 2016, Özkir et al., 2015). It follows that large stocks of materials are stored into cities, in buildings and infrastructure, where EEEs are present in large quantities. These 
stocks may represent a large potential resource that would become available for the reuse at the end of the product lifetime (Brunner, 2011).

Electrical and electronic industries have the responsibility to cope with the challenge about increasing resource consumption by putting into practice innovative and sustainable processes and products based on design for disassembly, recyclability, etc. Considering these, urban mining becomes the new juncture for applying circular economy at urban level. This means that urban areas have to be rescheduled as sustainable districts applying circular models to close the loop of this huge stream of goods. In fact, the e-waste generation at a global scale in 2016 was around 44.7 million metric tons (Mt), i.e. $6.1 \mathrm{~kg}$ per person., and it is expected to grow to $52.2 \mathrm{Mt}$ in 2021 (Baldé et al., 2017), with an annual growth rate of 3 to $5 \%$ (Agamuthu et al., 2015). The most urgent problem related to this trend is the management of toxic material included in electrical electronic equipment waste (WEEE) that may cause serious damage to the environment and have negative effects on human health. Hazardous materials typically involved in EEs are Lead (used in glass panels and gasket in computer monitors, solder in printed circuit boards and other components), Cadmium (used in chip resistors, infra-red detectors, semiconductor chips and battery), Mercury (used in thermostats, sensors, relays, switches) and Chromium VI (used for corrosion prevention of untreated and galvanized steel plates and as a decorative or hardener for steel housings) (Hagelüken, 2008). Consequently, landfilling, as endof-life option for EEEs, not only strategically affects land occupation but also can cause air, water and soil pollution, while incineration may result in remarkable gaseous and particulate emissions. It is, therefore, crucial to manage the resulting WEEE properly in a sustainable development perspective (Gutiérrez et al., 2010). Currently, one third of European WEEE is being reported by compliance schemes as separately collected and appropriately managed (note that it might partially be accomplished via destinations outside the Member State of origin of EU). From 2016 onwards, the minimum collection rate shall be $45 \%$, based on the total weight of WEEE collected in the Member State on a yearly basis, expressed as a percentage of the average weight of EEE placed on the market in the previous three years in the same Member State. The remaining WEEE is either 1) collected by unregistered enterprises and properly treated 2) collected by unregistered enterprises and improperly treated or even illegally exported abroad or 3) disposed of as part of residual waste (e.g. to landfills or incinerators). The problem gets worse if WEEE are illegally disposed (Li et al., 2012). The traditional illegal waste treatment is the disposal in open land, using primitive methods such as manual dismantling, open burning and acid leaching, rather than being properly extracted for reuse and recycling (Awasthi et al., 2016). According to a UNEP - United Nations Environment Program, a study on e-waste trafficking in 2013 reveals that most of the e-waste originating from the developed countries (European Union, the U.S., Japan, and Korea) has illegally destined to developing countries, especially India and China. The developed countries are also shipping out their used EEEs by incorrectly labelling them as electronic goods or as direct donations to institutions in developing countries (Yedla, 2016). However, the vision about electrical and electronical goods could change due to the presence of rich fraction of Copper, Gold, Nickel, Palladium and Silver in the EEEs (Bigum et al., 2012) and valuable bulky materials, such as Iron and Aluminum, along with plastic fractions, would definitely change. Overall, United Nations University estimates that the resource perspective for secondary raw materials from e-waste is worth 55 Billion $€$ of raw materials (Baldé et al., 2017).

Restoration, refreshing, reuse and recycling actions can contribute to impact's reduction throughout the life cycle of the equipment, from the extraction of raw materials to the production and marketing. This is the approach proposed at the University of Bologna to manage the huge amount of disused EEE generated by the various research activities ongoing. Almost every research and teaching activity is driven by or depends on electronic devices, every general activity relies on computers and each laboratory, office, classroom has, at least, a computer. The increasing digitalization on research activities, especially on Artificial Intelligence (AI), mobile, social and Internet of Things (IOT) applications where the generation of huge quantities of digital data needs to be digitally captured, stored, and processed, leads to an higher demand for hardware, especially for storage and processing, such as high-performance servers, and obviously, on WEEE production (https://www. cbi.eu/market-information/electronics-electrical-engineering/trends/). Universities experienced a rapid growth in innovative EEEs and, at the same time, a quick increase in the number of obsolete equipment sent to disposal.

In 2012, Remedia, an Italian consortium promoting services for the integrated handling of end-of-life EEE, (batteries and accumulators) established at UNIRe a free program for collection and recycling of University WEEE. The estimation of WEEE flows in 2015, handled in the major Italian Universities and managed by Remedia, is reported in the Table 1. It is shown that a high amount of WEEE is produced in just a limited sample of Italian universities. Re-

TABLE 1: WEEE flows from Italian Universities to Remedia - 2015 - Source: Remedia

\begin{tabular}{|c|c}
\hline Italian University & WEEE collected by Remedia (Kg) \\
\hline Technical university of Milano & 33.055 \\
\hline University of Milano & 29.100 \\
\hline University of Bologna & 14.500 \\
\hline University of Roma & 14.700 \\
\hline University of Siena & 13.850 \\
\hline University of Trieste & 13.640 \\
\hline Technical university of Torino & 10.700 \\
\hline University of Parma & 10.500 \\
\hline University of Modena - Reggio Emilia & 7.150 \\
\hline University of Catania & 6.900 \\
\hline University of Napoli & 6.650 \\
\hline University of Pavia & 3.900 \\
\hline Others & 32.400 \\
\hline
\end{tabular}


media managed about $14500 \mathrm{~kg}$ of University of Bologna WEEE.

WEEE are codified trough the European Waste Code (EWC), according to European Waste Catalogue and Hazardous Waste List (Environmental Protection Agency, 2002; European Commission, 2000), by defining the right code for the identification of product and process. EWC describes adequately the responsible management toward the proper end-of-life (EoL), i.e. waste being transported, handled or treated. The most common WEEEs generated at the Universities are hardware and computers, cathode ray tube (CRT) monitors, electric and electronic components, cables and refrigerators, which are respectively codified as 160214, 160213, 160216, 160211 EWCs. Table 2 shows Italian Universities' WEEE production in $\mathrm{kg}$, for each EWC, collected by Remedia during the period $2012-2015$.

The WEEEs outnumber all other waste fractions generated by the Universities or by a University, suggesting that Universities can be considered urban mines.

In fact, as it is universally recognized the fact that this kind of waste represents the main sector where an urban mining activity could be designed in order to maximize the life cycle of products and to exploit useful, precious and rare materials with a very high efficiency of separation.

\section{CASE STUDY AT THE UNIVERSITY OF BOLO- GNA: THE RAEEUSE LAB}

The huge amount of WEEE disposed every day by the University of Bologna has suggested and motivated the opening of the rAEEuse lab in which trashware activities about restoration of IEEE are performed. The case study on a centralized management system to collect, prepare for reuse and recover most of the end-of-service life informatics equipment is carried out at the Department of civil, chemical, environmental and materials engineering (DICAM) in which education and research activities are carried on by powerful and advanced electrical and electronic equipment remains. The rAEEuse lab, planned in a bottom up approach, manages disused University IEEEs, pursuing research activities related to circular economy and digitalization. In accordance with EU priorities, the proper management goal of disused IEEEs is primarily to maximize the rate of reuse, trying to repair inoperative equipment or part of them. The project involves many economic, social and environmental benefits according to the university sustainability policy. The project design has been anticipated by a study of feasibility of the progressive adaptation of the laboratory at the total amount of waste managed by the University of Bologna.

The e-waste stream has been controlled and monitored since the 2012, year in which the UNIRe project was implemented. In Figure 1 WEEE streams, from 2012 to 2015, are reported.

Laptops and computers, together with cables and electrical and electronic components, are typically recyclable and cover more than a half of the entire stream of disused EEE (referred, when are waste, to the EWC 160214 and 160216).

The project is designed with the aim of extending the value chain of this type of IEEE maximizing their time span (Figure 2). Nowadays, the University management of IEEE is unfortunately set on the make-use-dispose model: a computer begins decrease its performance after three

TABLE 2: WEEE flows from Italian University to Remedia, for each EWC - 2012/2015 (kg/y) - Source: Remedia

\begin{tabular}{|c|c|c|c|}
\hline IWEE from University to Remedia & $2012 / 2013$ & $2013 / 2014$ & $2014 / 2015$ \\
\hline 160214 EWC (PCs, printers) & $142.375 \mathrm{Kg}$ & $164.898 \mathrm{Kg}$ & $135.351 \mathrm{Kg}$ \\
\hline 160213 EWC (CRT monitors) & $69.850 \mathrm{Kg}$ & $104.162 \mathrm{Kg}$ & $62.206 \mathrm{Kg}$ \\
\hline $\begin{array}{l}160216 \text { EWC (electric and electronic } \\
\text { components and cables) }\end{array}$ & $1.336 \mathrm{Kg}$ & $2.823 \mathrm{Kg}$ & $3.724 \mathrm{Kg}$ \\
\hline Others & $5.082 \mathrm{Kg}$ & $3.602 \mathrm{Kg}$ & $16.646 \mathrm{Kg}$ \\
\hline Total & $218.373 \mathrm{Kg}$ & $275.485 \mathrm{Kg}$ & $217.927 \mathrm{Kg}$ \\
\hline
\end{tabular}

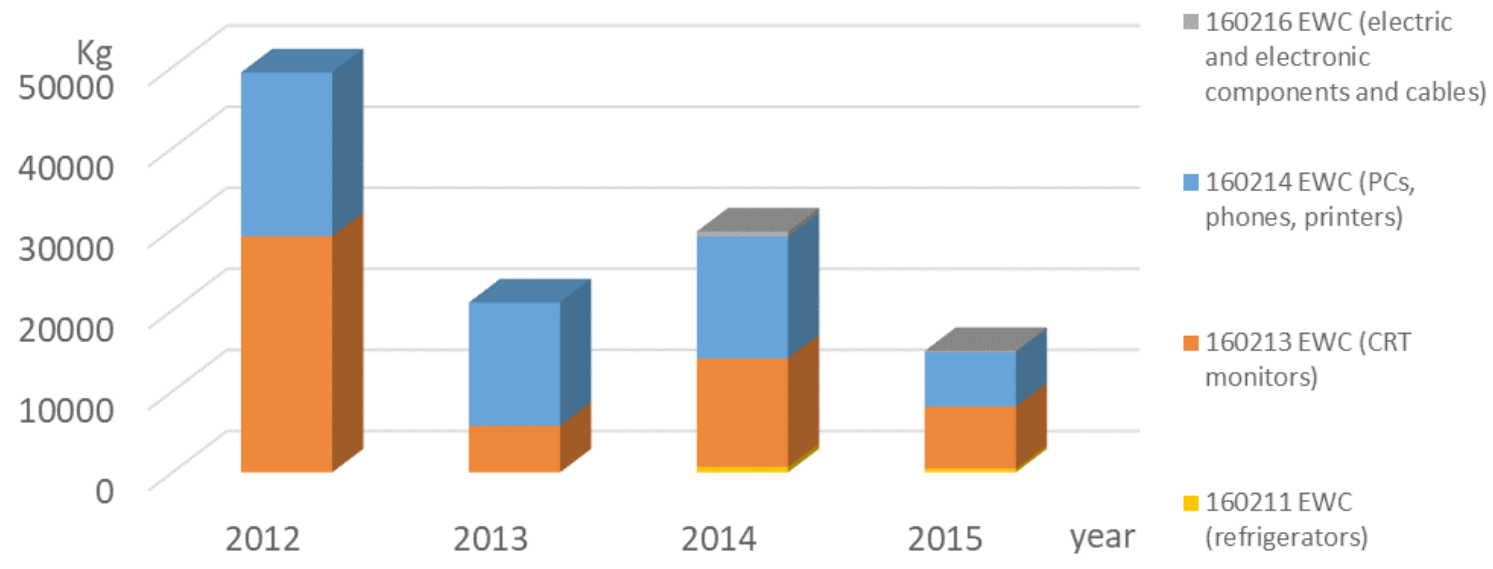

FIGURE 1: University of Bologna, WEEE stream (2012-2015). 
years becoming incompatible with research activities, and so it is ready to disposal. The restoration activity allows the improving of performance giving to IEEE a second life.

A pilot test has been implemented to verify the feasibility setoff setting up the process, whose plan, shown in the Figure 3, illustrates the long-term strategy for university IEEE management.

More specifically, the rAEEuse lab manages disused equipment that in the past was directly sent to disposal. As shown in the Figure 4, all the input IEEE flow are analyzed through CPU-Z software that reveals the hardware components characteristics and performances. If the obsolescence does not permit the restoration, devices are dismantled manually, allowing to recover hard disk and other components. If IEEE are obsolete, materials are separated and unusable components collected. Once the reusable fraction is separated and/or repaired, the remaining flux is stored as proper waste and, due to the high quality and good collection and separation; it can be given to waste Management Company or consortium at very convenient economic conditions. Precious metals can be extracted from obsolete components thank to the collaboration with local SMEs that can take out any rare-earth and strategic metals (e.g. lanthanum, thulium and neodymium) through advanced metallurgical technologies (Işıldar, et al. 2018, Reuter et al., 2013; Tuncuk et al., 2018; Zhang et al., 2016; Graedel et al.,2011). Both regenerated PCs and recovered components can be reused within University or can be activated a virtuous process of donation to local community (no profit association, school, etc.).

The insight of the rAEEuse lab was born within a University course involving several engineering students. The feasibility was investigated by the University group "Terracini in Transizione", a living lab of students, researchers, academics and technicians, in collaboration with Nu.Te. R. (Nucleo Tecnico Rifiuti, i.e. the university waste technical unit). The method used for planning the activities in the lab is based on the transition thinking theory (Hopkins, 2009). The transition research refers to an interdisciplinary research field focused on structural change in societal systems (Wittmayer et al., 2017), with a multi-level perspective (MLP). In fact, the lab was carried on by students and researchers that, using a "bottom up" approach, have involved technicians and academics, pursuing a systematic

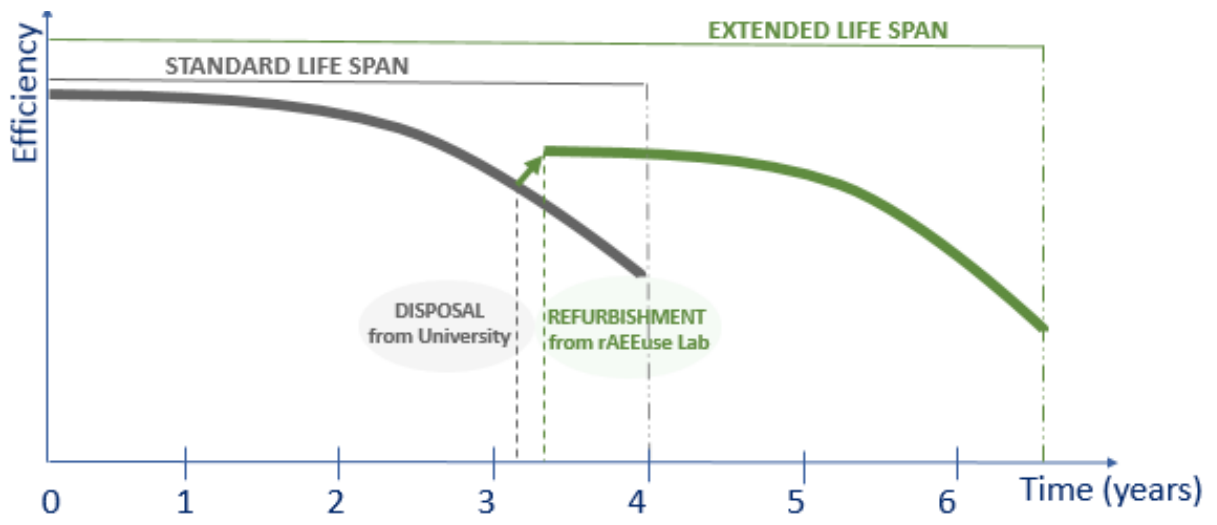

FIGURE 2: rAEEuse lab, the vision.

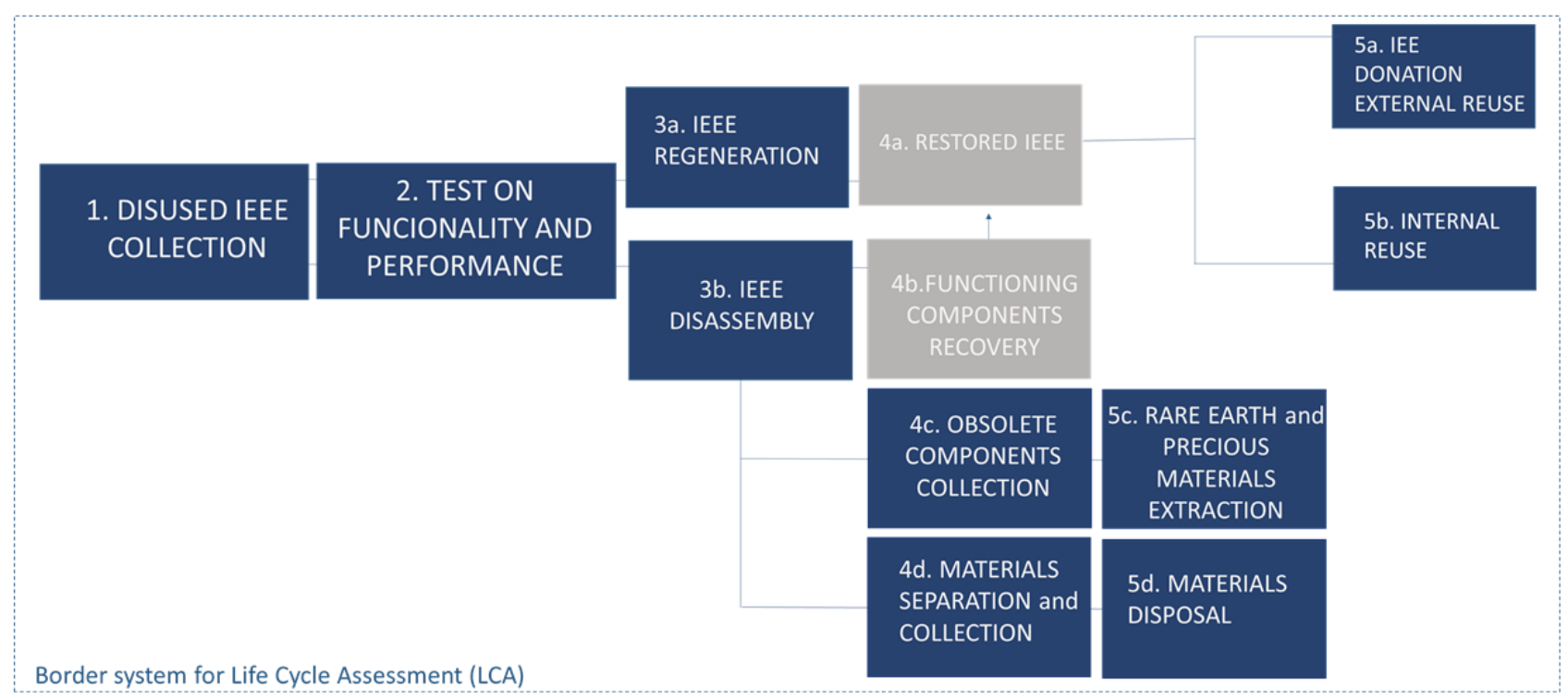

FIGURE 3: rAEEuse lab, the long-term strategy. 


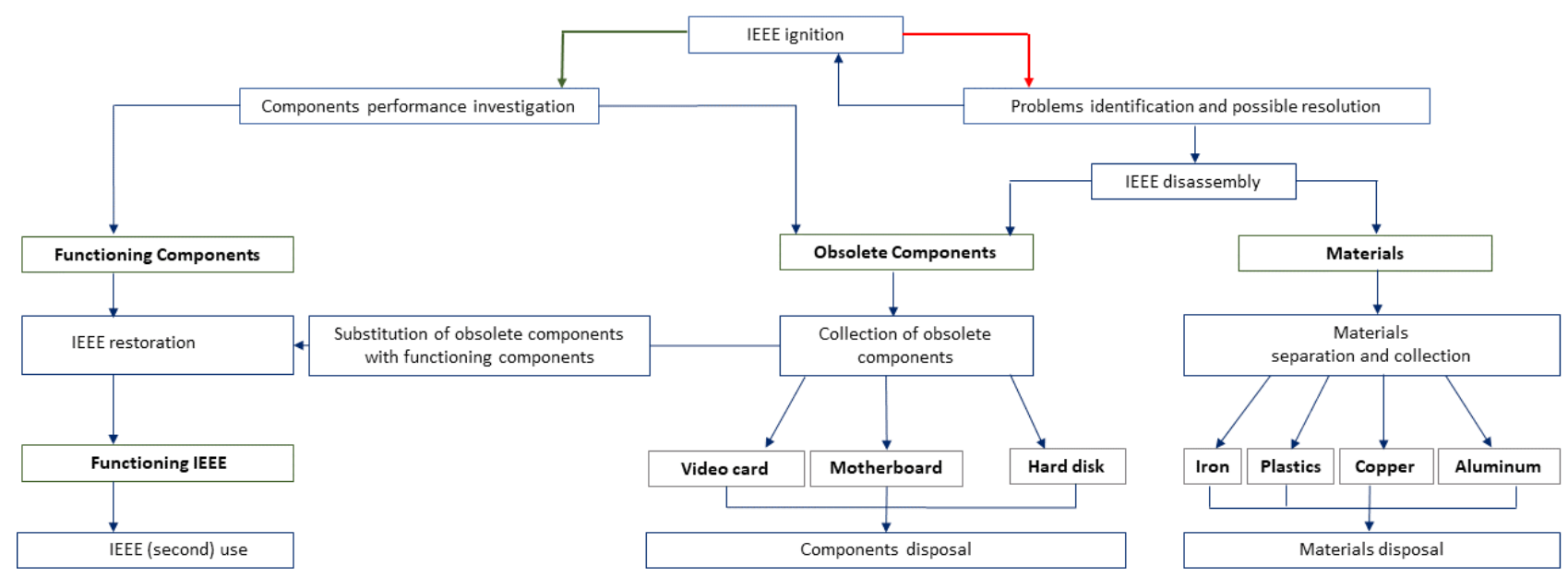

FIGURE 4: rAEEuse lab, the process.

innovation inside university, enabling the interactions at different levels and demonstrating then how different levels can be combined and can interact (Devolder et al., 2015).

\section{RESULTS AND DISCUSSION}

The experimentation has involved 19 computer facilities almost at the end of their service life by DICAM. Regarding these, 5 equipment have been restored while 14 have been disassembled. The restoration has been carried on by the replacement of Random Access Memory (RAM) with the most efficient ones. Instead, the disassembly has aimed to components and materials extraction. From a primary extraction operation, iron, plastic, aluminum have been manually recovered. An additional manual extraction has been done to get back copper from obsolete components and cables. All type of components and materials have been collected, separated and weighed to register data in a specific database. This database classifies all the available components (Motherboard, Processor, RAM, Video Card, power supply, Hard disk, Audio card, sink, Keyboard and Mouse) with a code, as shown in the Figure 5, thus identifying component types, properties and location in the lab. A dataset, containing detailed information on resources and processes, has included allowing the performing of a Life Cycle Assessment (LCA) and Life Cycle Cost (LCC) study. Database, supporting the outline of LCA and LCC studies, takes into account the assessment of duty and the responsibility in matter of privacy and the protection of data recorded inside the hard disks (Bonoli et al., 2013).

The average composition of an IEEE shown in Figure 6, reveals that, iron covers the bigger part of total composition of typical computers, followed by functioning and obsolete components. Taking into account the overall amount of components, the $55,7 \%$ wt is reusable, compared to the $44,3 \%$ wt that is obsolete.

While functioning components have been stored for future applications, the obsolete components have been collected to valorize printed circuit boards (PCBs). Their importance, from an economic and environmental point of view, relies in the metals present (high concentration and purity), and in the hazardous nature of some of its constituents (Choubey et al., 2015). In fact, PCB may contain about $250 \mathrm{~g} / \mathrm{t}$ of gold, which has very high values compared to the gold ores with concentrations between 1 and $10 \mathrm{~g} / \mathrm{t}$ (Tuncuk et al., 2012). However, the process to recover precious metals from EEE involves consists in pyrometallurgical, hydrometallurgical and bioprocesses, particularly different in terms of energy consumption.

The current challenges of rAEEuselab are related to the identification of sustainable separation and extraction processes to recover rare earth and precious metals from PCBs. In fact, while the pretreatment related to components extraction and materials collection, are manual processes, the metallurgical processes are much more difficult and impactful. LCA methodology permits to compare different operations in terms of environmental impacts and energy consumption and it can help decision-making processes about which End of Life (EoL) strategy is better to adopt for the critical resources extraction.

Considering the hydrometallurgical process performed by ENEA (Italian National Agency for New Technologies, Energy, Sustainable Economic Development) on end of life (EoL) household computers, results reveal a good percent-

\section{SV-T3-09}

\section{Components type:}

$\mathrm{SV}=$ Video card; $\mathrm{SM}=$ Motherboard; $H D=$ Hard disk; $P=$ Processor; $R=$ RAM; etc.

\section{Properties components:}

T1, T2, T3 for different connections and attachments

Slot:

01,02,03 etc. for different warehouse slot lab

FIGURE 5: rAEEuse lab database, code example. 


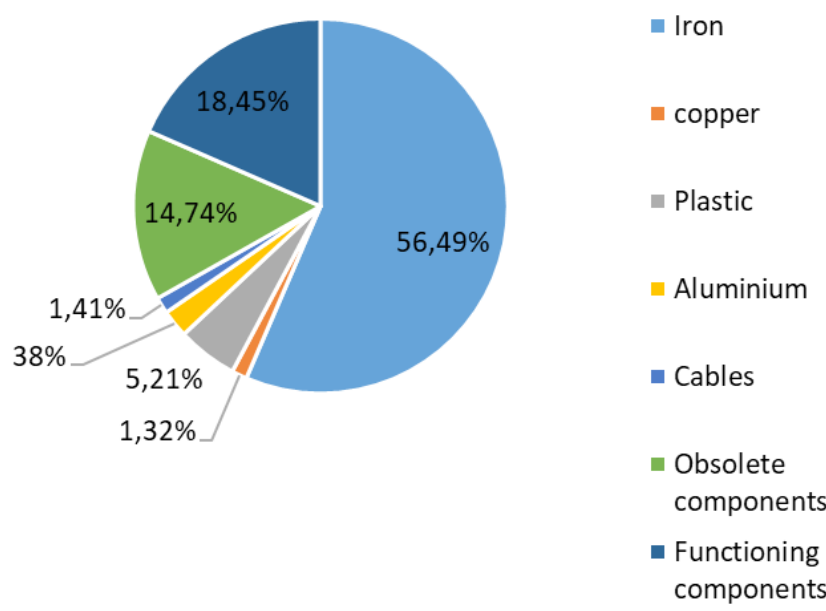

FIGURE 6: Average composition (by weight) of IEEE that has processed during the experimental stage in the rAEEuse lab.

age of metals recovery, as shown in the Table 3. A study on economic feasibility and profitability has been detailed, as shown in the Table 4.

In the past, disused EEE represented a problem due to the waste management and the high disposal costs, but today they can be considered as a source of resources, perfectly integrated with circular economy principles. In fact, before 2017, 19 IEEE were considered as waste to dispose, today, they have been managed as source to restoring 5 computers, valorizing precious metals and materials from 3 component restoration.

From the environmental point of view, the rAEEuse lab can be assumed consistent with the sustainable University policy. From the economic point of view, the fact that waste management costs have been reduced and revenues have been obtained by EE equipment and components valoriza-

TABLE 3: Potential value of $1 \mathrm{Kg}$ of PCB in October 2018.

\begin{tabular}{c|c|c} 
& Process recovery (g/Kg PCB) & Material value (EUR/g) \\
\hline $\mathrm{Ag}$ & 0,35 & 0,4 \\
\hline $\mathrm{Au}$ & 0,24 & 33,87 \\
\hline $\mathrm{Cu}$ & 129 & 0,004 \\
\hline $\mathrm{Pb}$ & 15 & 0,0017 \\
\hdashline $\mathrm{Sn}$ & 43 & 0,019 \\
\hline
\end{tabular}

TABLE 4: Potential revenue from obsolete EE components managed by rAEEuse lab during the experimental phase.

\begin{tabular}{|c|c|c|}
\hline \multicolumn{2}{|c|}{ Obsolete components (Kg) } & \multirow{2}{*}{$\begin{array}{c}\mathbf{2 , 0 9} \\
\begin{array}{c}\text { Estimated value for obso- } \\
\text { lete components (EUR) }\end{array}\end{array}$} \\
\hline Materials & $\begin{array}{l}\text { Material composition for } \\
\text { obsolete components }(\mathrm{g})\end{array}$ & \\
\hline $\mathrm{Ag}$ & 0,7315 & 0,293 \\
\hline $\mathrm{Au}$ & 0,5016 & 16,989192 \\
\hline $\mathrm{Cu}$ & 269,61 & 1,07844 \\
\hline $\mathrm{Pb}$ & 31,35 & 0053295 \\
\hline Sn & 89,87 & 1,70753 \\
\hline \multicolumn{2}{|c|}{$\begin{array}{l}\text { Total revenue for obsolete components } \\
\text { valorisation (EUR) }\end{array}$} & 18,414 \\
\hline
\end{tabular}

tion has added value to the lab. In addition to environmental and economic benefits, another important advantage is the disruptive system innovation going on at the University. The lab facilitates the university e-waste valorization and avoids the complexity, time and financial costs traditionally due to dispersive waste management, whilst ensuring that disused EEE is handled responsibly. In fact, while the procedure associated to waste disposal usually lasts many months owing to the hardworking practice related to University waste disposal according to the European waste directive, the average time to process a computer is about 15 minutes, thus permitting to cope with the overall amount of e-waste managed by the University of Bologna.

At the end, the lab has been putting into practices the so-called third mission of the University, generating public assets to the local community by donation directing the activities to a strong focus on socio-technological innovation in different socio-technical sub-systems or societal domains (Geels, 2002; Loorbach et al., 2010). However, this type of reality is already operational in the "trashware associations" throughout Italy and, in particular, at the University of Bologna at Cesena Campus, where a student association is funded by the municipality for refreshing disused computers. These practices could be extended to the city, starting by collaboration with companies and municipality that want to implement reuse and recycling of disused IEEEs. Moreover, the University of Bologna could potentially take advantage of its leadership inside the Italian universities for the sustainable development network (R.U.S.), to support other Universities to implement good practices for reuse and recycling of EEE but also to promote a clarification of ambiguous legislations.

\section{CONCLUSIONS}

The rAEEuse lab takes place in a favorable climate pushed by European regulation. The EU package on circular economy and its action plan (EU Commission, 2015; 2017), the policy recommendations like "European resource efficiency platform" (EREP, 2014), the European Cohesion Policy "Horizon 2014-2020" encourage the creation of dedicated paths for refurbishment, recovery and recycling of waste. This is also encouraged by the European WEEE regulatory (EU Directive 2012/19/UE), implemented in Italy in 2014 (D.L. 2014/49), where the new target of $45 \mathrm{~kg}$ of WEEE recovered is settled compared to $100 \mathrm{~kg}$ of EEE, placed on the market in the period 2016-2019. On the other side, this project, would take great advantage by a simpler and clearer local and national legislation, as well as many others in the field of circular economy.

In the University's context, the project represents an important contribution in the reduction of a remarkable quantity of EEE Waste (WEEE according with the prevention principles suggested by the Waste Hierarchy. The lab fits in the sustainable University policy and, is become an example of best practices of circular economy among all national Universities, having the potentiality to help to greatly reduce WEEE's environmental impact and to create a network of sustainability hotspots.

At the same time, the progressive broadening of this 
experience may contribute to reduce wider national and international problems, such as the large imports of metals and rare earths from China and South Africa and the illegal traffic of WEEE in developing countries. The appropriate recovery of disused EEE also helps to decrease the environmental damage caused by the improper disposal of them by the illegal international trade pathways. Therefore, limited action at local would help solving a big problem at a global scale, since each small action lays the foundation for the development of the transition.

It is also important to highlight that the Universities have the responsibility to provide leadership on education for sustainable development. They can apply a "learning-by-doing" approach in relation with the multiple challenges faced by the society and so they can influence actual and future decision makers. Education plays a crucial role especially in catalyzing proactive measures that can positively affect the present and the future. Due to its educational and institutional role, universities have an important role as research institution where innovative technologies can be developed, and sustainable operations can be put into practice (UNESCO, 2015). Universities can further facilitate the application of circular economy and sustainable development principles by a bottom up approach: not only through the activities of researchers and technicians, working to improve the efficiency of waste management and material substitutes to support resource productivity, but also engaging students as active participants in living lab initiatives like rAEEuse lab. In this way, they indirectly increase awareness about the importance of "closing-theloop" and promote more sustainable lifestyles, as well as the transition to a low carbon future.

\section{AKNOWLEDGEMENTS}

Authors would thank Climate Kic and European Institute for Innovation and Technology for their support to the project "Insight-Bonoli", APSP0011_2016-1.3.4-282_P125-08.

\section{REFERENCES}

Agamuthu, P., Kasapo, P., \& Mohd Nordin, N. A. (2015). E-waste flow among selected institutions of higher learning using material flow analysis model. Resources, Conservation and Recycling. https:// doi.org/10.1016/j.resconrec.2015.09.018

Awasthi, A. K., Zeng, X., \& Li, J. (2016). Environmental pollution of electronic waste recycling in India: A critical review. Environmental Pollution. https://doi.org/10.1016/j.envpol.2015.11.027

Baldé, C. P., Forti, V., Kuehr, R., \& Stegmann, P. (2017). The Global E-waste Monitor 2017: Quantities, Flows, and Resources. United Nations University.

Bigum, M., Brogaard, L., \& Christensen, T. H. (2012). Metal recovery from high-grade WEEE: A life cycle assessment. Journal of Hazardous Materials. https://doi.org/10.1016/j.jhazmat.2011.10.001

Bonoli, A., Ferroni, F., \& Prandstraller, D. (2013). Recovery and Preparing for Reuse of Disused Informatics Electrical and Electronic Equipment at the University of Bologna. Proceedings of SUM2014 2nd Symposium on Urban Mining 2013, Sardinia (IT).

Bonoli A, Cappellaro F. (2014). Waste Responsibility and Management. The case of the University of Bologna. In: Proceedings of SUM2014 2nd Symposium on Urban Mining 2014, Bergamo (IT).

Borthakur, A., \& Govind, M. (2017). Emerging trends in consumers' E-waste disposal behaviour and awareness: A worldwide overview with special focus on India. Resources, Conservation and Recycling. https://doi.org/10.1016/j.resconrec.2016.11.011
Brunner, P. H. (2011). Urban mining a contribution to reindustrializing the city. Journal of Industrial Ecology. https://doi.org/10.1111/ j.1530-9290.2011.00345.x

Çetinsaya Özkir, V., Efendigil, T., Demirel, T., Çetin Demirel, N., Deveci, M., \& Topçu, B. (2015). A three-stage methodology for initiating an effective management system for electronic waste in Turkey. Resources, Conservation and Recycling. https://doi.org/10.1016/j. resconrec.2015.01.008

Choubey, P. K., Pateria, S., Saxena, A., Vaisakh Punnekkattu Chirayil, S. B., Jha, K. K., \& Sharana Basaiah, P. M. (2015). Power efficient, bandwidth optimized and fault tolerant sensor management for IOT in Smart Home. In Souvenir of the 2015 IEEE International Advance Computing Conference, IACC 2015. https://doi.org/10.1109/IADC. 2015.7154732

Cui, J., \& Forssberg, E. (2003). Mechanical recycling of waste electric and electronic equipment: A review. Journal of Hazardous Materials. https://doi.org/10.1016/S0304-3894(03)00061-X

Devolder, S., \& Block, T. (2015). Transition thinking incorporated: Towards a new discussion framework on sustainable urban projects. Sustainability (Switzerland). https://doi.org/10.3390/su7033269

European Parliament. (2017). Circular Economy Package: Four Legislative Proposals on Waste. Eu Legislation in Progress. Briefing.

European Commision. (2015). An EU action plan for the circular economy. Com. http://doi.org/10.1017/CBO9781107415324.004

European Commission (2012). Legislation and secondary legislation on waste electrical and electronic equipment (WEEE). (http:// ec.europa.eu/environment/waste/weee/legis_en.htm).

Environmental Protection Agency. (2002). European waste catalogue and hazardous waste list. Hazardous Waste.

European Commission. (2000). Commission Decision on the European List of Waste (COM 2000/532/EC). Official Journal of the European Communities. (2000/532/EC)

European Commission, European Cohesion Policy 2014-2020 (http:// ec.europa.eu/regional_policy/en/policy/how/priorities/)

Ferrari A., Grasselli L., Montanari P. (2016). WEEENmodels. La gestione sostenibile dei rifiuti elettrici ed elettronici (RAEE). Book. Aracne editor.

Geels, F. W. (2002). Technological transitions as evolutionary reconfiguration processes: A multi-level perspective and a case study. Research Policy. https://doi.org/10.1016/S0048-7333 (02)00062-8

Graedel, T. E., \& Et.Al. (2011). UNEP Recycling rates of metals - A Status Report, a Report of the Working Group on the Global Metal Flows to the international Resource Panel. Group. ISBN 978-92-807-3161-3

Gu, Y., Wu, Y., Xu, M., Wang, H., \& Zuo, T. (2016). The stability and profitability of the informal WEEE collector in developing countries: A case study of China. Resources, Conservation and Recycling. https://doi.org/10.1016/j.resconrec.2015.12.004

Gutiérrez, E., Adenso-Díaz, B., Lozano, S., \& González-Torre, P. (2010). A competing risks approach for time estimation of household WEEE disposal. Waste Management. https://doi.org/10.1016/j. wasman.2010.02.032

Hagelüken, C. (2008). Mining our computers -opportunities and challenges to recover scarce and valuable metals from end-of-life electronic devices. Electronic Goes Green 2008+.

Hopkins, R. (2009). The transition handbook: from oil dependency to local resilience. UIT Cambridge Ltd. https://doi.org/10.1080/095 81596.2010.507961

Işıldar, A., Rene, E. R., van Hullebusch, E. D., \& Lens, P. N. L. (2018). Electronic waste as a secondary source of critical metals: Management and recovery technologies. Resources, Conservation and Recycling. https://doi.org/10.1016/j.resconrec.2017.07.031

Li, J., Lopez N., B. N., Liu, L., Zhao, N., Yu, K., \& Zheng, L. (2013). Regional or global WEEE recycling. Where to go? Waste Management. http://doi.org/10.1016/j.wasman.2012.11.011

Loorbach, D., \& Rotmans, J. (2010). The practice of transition management: Examples and lessons from four distinct cases. Futures. https://doi.org/10.1016/j.futures.2009.11.009

Ongondo, F. O., Williams, I. D., \& Cherrett, T. J. (2011). How are WEEE doing? A global review of the management of electrical and electronic wastes. Waste Management. https://doi.org/10.1016/j. wasman.2010.10.023

UNEP, \& Reuter, M. (2013). Metal Recycling: Opportunities, Limits, Infrastructure. United Nations Environmental Programme.ISBN 97892-807-3267-2

UNEP. (2009). Recycling - from E-Waste to Resources. Sustainable Innovation and Technology Transfer Industrial Sector Studies. 
Tuncuk, A., Stazi, V., Akcil, A., Yazici, E. Y., \& Deveci, H. (2012). Aqueous metal recovery techniques from e-scrap: Hydrometallurgy in recycling. Minerals Engineering. https://doi.org/10.1016/j.mineng.2011.09.019

Wittmayer, J. M., Avelino, F., van Steenbergen, F., \& Loorbach, D. (2017). Actor roles in transition: Insights from sociological perspectives. Environmental Innovation and Societal Transitions. http://doi. org/10.1016/j.eist.2016.10.003
Yedla, S. (2016). Development of a methodology for electronic waste estimation: A material flow analysis-based SYEWaste Model. Waste Management and Research. https://doi. org/10.1177/0734242X15610421

Zhang, L., \& Xu, Z. (2016). A review of current progress of recycling technologies for metals from waste electrical and electronic equipment. Journal of Cleaner Production. https://doi.org/10.1016/j. jclepro.2016.04.004 